\title{
Soil moisture storage and hillslope stability
}

\author{
A. Talebi ${ }^{1,2}$, R. Uijlenhoet ${ }^{1}$, and P. A. Troch $^{3}$ \\ ${ }^{1}$ Chair of Hydrology and Quantitative Water Management, Wageningen University, Wageningen, The Netherlands \\ ${ }^{2}$ Faculty of Natural Resource, Yazd University, Yazd, P.O. Box 89195-741, Iran \\ ${ }^{3}$ Department of Hydrology and Water Resources, The University of Arizona, Tucson, AZ 85721, USA
}

Received: 21 June 2007 - Revised: 10 September 2007 - Accepted: 10 September 2007 - Published: 12 September 2007

\begin{abstract}
Recently, we presented a steady-state analytical hillslope stability model to study rain-induced shallow landslides. This model is based on kinematic wave dynamics of saturated subsurface storage and the infinite slope stability assumption. Here we apply the model to investigate the effect of neglecting the unsaturated storage on the assessment of slope stability in the steady-state hydrology. For that purpose we extend the hydrological model to compute the soil pore pressure distribution over the entire flow domain. We also apply this model for hillslopes with non-constant soil depth to compare the stability of different hillslopes and to find the critical slip surface in hillslopes with different geometric characteristics. In order to do this, we incorporate more complex approaches to compute slope stability (Janbu's non-circular method and Bishop's simplified method) in the steady-state analytical hillslope stability model. We compare the safety factor $(F S)$ derived from the infinite slope stability method and the more complex approach for two cases: with and without the soil moisture profile in the unsaturated zone. We apply this extended hillslope stability model to nine characteristic hillslope types with three different profile curvatures (concave, straight, convex) and three different plan shapes (convergent, parallel, divergent). Overall, we find that unsaturated zone storage does not play a critical role in determining the factor of safety for shallow and deep landslides. As a result, the effect of the unsaturated zone storage on slope stability can be neglected in the steady-state hydrology and one can assume the same bulk specific weight below and above the water table. We find that steep slopes with concave profile and convergent plan shape have the least stability. We also demonstrate that in hillslopes with non-constant soil depth (possible deep landslides), the ones with convex profiles and convergent plan shapes have slip surfaces with the minimum safety factor near the outlet region. In general,
\end{abstract}

Correspondence to: A. Talebi

(ali.talebi@wur.nl) when plan shape changes from divergent to convergent, stability decreases for all length profiles. Finally, we show that the applied slope stability methods and steady-state hydrology model based on the relative saturated storage can be used safely to investigate the relation between hillslope geometry and hillslope stability.

\section{Introduction}

Slope instability in steep mountainous terrain is a major problem to land managers worldwide. One of the types of hillslope instability occurs in the form of shallow landslides. Shallow landslides are one of the most common types of landslides in steep, soil-mantled landscapes in different climate zones. Recently, theoretical models have been developed to predict how landslide susceptibility depends on topographic and hydrologic variables (e.g. Sidle, 1992; Montgomery and Dietrich, 1994; Wu and Sidle, 1995; Borga et al., 2002; Van Beek, 2002; Claessens, 2005). In all of these models, topography has been introduced as a factor affecting slope stability. The effect of terrain on soil pore pressure during periods of extended rainfall has been modeled in two ways: by means of topographic (wetness) indices (e.g. Montgomery and Dietrich, 1994; Claessens, 2005; Rosso et al., 2006) and through detailed modeling of the 3-D flow processes along hillslopes (e.g. Cai et al., 1998; Wilkinson et al., 2000). Montgomery and Dietrich (1994) presented a simple model for the topographic influence on shallow landslide initiation by combining a contour-based steady-state hydrologic model with the infinite slope stability model to define slope stability classes based upon slope and specific drainage area. Montgomery et al. (1998) developed this model further (SHALSTAB) to evaluate slope instability associated with the potential occurrence of shallow landsliding. Although several applications show this approach to be capable of capturing the spatial variability of shallow landslide hazard, it

Published by Copernicus Publications on behalf of the European Geosciences Union. 
only accounts for straight hillslopes with infinite length profile, neglecting other topographic characteristics (e.g. plan shape and profile curvature, as well as variable soil depth).

Anderson and Kemp (1991) presented a combined detailed hydrology and stability model (CHASM) that allows the simulation of changes in pore water pressures in response to individual rainfall events, and consider their role in maintaining slope stability. Further developments of this model presented by Wilkinson et al. (2002) couples dynamic modeling of the hydrology with Janbu's non-circular slip surface stability analysis (Janbu, 1954), accounting for soil cohesion, slope plan topography and vegetation.

To investigate the key role of geometric characteristics of hillslopes (plan shape and profile curvature) on shallow landslides, Talebi et al. (2007) presented a steady-state analytical hillslope stability model based on kinematic wave subsurface storage dynamics. Their analytical approach is similar to the method of Montgomery and Dietrich (1994) in that it combines steady-state hydrologic concepts with the infinite slope stability model, but has an important difference. Talebi et al. (2007) presented a complete analytical expression for the computation of the factor of safety $(F S)$ for finite hillslopes. Possible shortcomings of their approach, however, are that the analytical model does not include the effect of unsaturated storage on slope stability, and that it applies infinite slope stability computations to finite hillslope types. The first purpose of this study is to investigate the appropriateness of those simplifying assumptions (neglecting the unsaturated zone storage and the infinite slope stability approach) for the accurate determination of the factor of safety for shallow landslides. Therefore, in this paper, the infinite slope stability method is replaced by more complex approach (Janbu's noncircular method and Bishop's simplified method) to compute the stability and the critical slip surface in hillslopes with different geometric characteristics and different soil depth (to allow for possible deep landslides). The latter approach is similar to Wilkinson et al. (2002) but it considers unsaturated zone storage by computing vertical soil moisture profiles from steady-state solutions to Richards' equation (Rockhold et al., 1997).

Section 2 briefly summarizes the development of the steady-state analytical hillslope stability model (Talebi et al., 2007). This model computes the space-time evolution of saturated storage along hillslopes by means of the mass conservation equation and a kinematic form of Darcy's equation (Troch et al., 2002). The steady-state storage profile corresponding to a given recharge rate forms the basis for the slope stability analysis. The infinite slope stability model leads to an analytical expression for the factor of safety as a function of position along the hillslope.

In Sect. 3 we present an extension to the hydrological component of this model that accounts for unsaturated zone storage based on steady-state solutions to the 1-D Richards' equation (Rockhold et al., 1997). With respect to the influence of soil suction on soil cohesion (Fredlund, 1978), we also investigate the effect of the unsaturated zone storage on soil cohesion and thus slope stability. Therefore, the safety factor will be calculated with and without considering the soil moisture profiles in the unsaturated zone.

As soil depth usually is not constant and failures are often non-parallel to the bedrock (due to hydrological and geological discontinuities within the hillslope profile), the infinite slope stability assumption needs to be relaxed. In Sect. 4 we further extend the model to compute the factor of safety by using Bishop's circular method and Janbu's noncircular method. Bishop's method assumes zero interslice shear forces, satisfies moment equilibrium around the center of the circular failure surface and satisfies vertical force equilibrium. The Janbu method assumes that failure occurs through sliding of a block of soil on a non-circular slip surface. In this paper, we use Bishop's method to find the critical slip surface and Janbu's method to compare the stability of hillslopes with a common slip surface.

Section 5 explains the main results of the paper and describes the application of the analytical model and the more complex approach to investigate the stability of nine different hillslope types with a constant length scale. We generalize our results by studying the relation between slope angle, profile and plan curvature, and landform stability (with and without the effect of unsaturated zone storage). Hillslope stability is studied for two cases (constant and non-constant soil depth). The focus of this paper lies in a comparison of the two cases of slope stability analysis to determine the role of hillslope geometry (profile curvature and plan shape) on hillslope stability with and without considering the unsaturated zone storage. The first case is based on infinite slope assumption (constant soil depth) and the second one is based on Janbu's non-circular method (1954) and Bishop's simplified (1955) method (non-constant soil depth). Finally, Sect. 6 summarizes the main results of the paper.

\section{Steady-state analytical hillslope stability model}

Here we summarize the main features of the hillslope stability model recently developed by Talebi et al. (2007). This model applies to catchments with moderate to steep terrain and shallow, permeable soils where subsurface storm flow is the dominant flow mechanism. To study the effect of topography on rain-induced shallow landsliding, the hillslopes of such catchments are characterized by the combined curvature in the gradient direction (profile curvature) and the direction perpendicular to the gradient (contour or plan curvature). The profile curvature is important because it controls the change of velocity of mass flowing down the slope and the plan curvature defines topographic convergence which is an important control on subsurface flow concentration (Troch et al., 2002). Other investigations (e.g. Montgomery and Dietrich, 1994; Borga et al., 2002; Hennrich and Crozier, 2004) have also shown that shallow landslides are strongly 
controlled by subsurface flow convergence. The surface of an individual hillslope is represented by the following bivariate function (Evans, 1980):

$z(x, y)=E+H(1-x / L)^{n}+\omega y^{2}$

where $z$ is the elevation, $x$ is the horizontal distance measured in the downstream length direction of the surface, $y$ is the horizontal distance from the slope centre in the direction perpendicular to the length direction (the width direction), $E$ is the minimum elevation of the surface above an arbitrary datum, $H$ is the maximum elevation difference defined by the surface, $L$ is the total length of the surface, $n$ is a profile curvature parameter, and $\omega$ is a plan curvature parameter. Allowing profile curvature (defined by $n$ ) to assume values less than, equal to, or greater than 1 and plan curvature (defined by $\omega$ ) to assume either a positive, zero, or negative value, one can define different basic geometric relief forms. Subsurface flow processes are influenced by plan and profile curvatures and the hydraulic properties of the porous medium. The mathematical description of these flow processes results in the formulation of the 3-D Richards equation which is difficult to solve analytically and numerically. One way to overcome this problem is to reduce the dimensionality by introducing the subsurface storage capacity function defined by the hillslope width at flow distance $x$, the average soil depth at that distance and the effective porosity. Assuming kinematic wave subsurface flow, Troch et al. (2002) derived the following analytical expression for steady-state saturated storage of the hillslope:

$S(x)=\frac{f L}{n k_{s} H}\left(1-\frac{x}{L}\right)^{1-n} N A(x)$

where $f$ is the drainable porosity, $k_{s}$ is the saturated hydraulic conductivity, $N$ is the (constant) recharge rate, $A(x)$ is the upstream drainage area at location $x$ and $S(x)$ represents the saturated storage at a given distance $x$ from the divide. Dividing by the storage capacity function, $S c$ one finds the relative saturated storage:

$\sigma(x)=\frac{S(x)}{S_{c}(x)}$

The variable $\sigma$ describes the steady-state wetness of the soil. Note that $S_{c}(x)=f w(x) D(x)$ where $w(x)$ is the hillslope width function and $D(x)$ is the (width-averaged) soil depth at distance $x$.

Slope stability studies are based on the calculation of the factor of safety $(F S)$ considering a failure surface. For hillslopes it is common to define the safety factor as the ratio of the available shear strength to the minimum shear strength needed for equilibrium. With stability expressed by the factor of safety, $F S$, the infinite slope stability equation is given by (Wu and Sidle, 1995; Van Beek, 2002):

$F S(x)=\frac{c_{t}+\left[(D-h(x)) \gamma_{m}+h(x) \gamma_{b}\right] \cos ^{2} \beta \tan \phi}{\left[(D-h(x)) \gamma_{m}+h(x) \gamma_{s}\right] \sin \beta \cos \beta}$ where $c_{t}$ is the total soil cohesion, $\phi$ is the angle of internal friction, $D$ is the depth to the shear plane (vertical soil depth), $\beta$ is the slope angle, $h$ is the water level above this plane, and $\gamma_{m}, \gamma_{s}$ and $\gamma_{b}$, are respectively the moist, saturated and buoyant bulk specific weights (the buoyant bulk specific weight is defined as $\left.\gamma_{b}=\gamma_{s}-\gamma_{w}\right)$. Applying Eq. (4) together with the solution for $\sigma(x)$ (Eq. 3), and by assuming the same soil density for whole soil profile (above and below the water table), Talebi et al. (2007) presented the following simple equation to compute the shallow landslide safety factor for cohesionless soils:

$$
\overline{F S}=\frac{\int_{0}^{L}\left[1-\sigma(x)\left(\frac{\rho_{w}}{\rho_{s}}\right)\right] \cos ^{2} \beta(x) d x \tan \phi}{\int_{0}^{L} \sin \beta(x) \cos \beta(x) d x}
$$

where $\rho_{w}$ and $\rho_{s}$ are the density of water and saturated soil, respectively.

\section{Incorporating the unsaturated zone storage}

The computation of $\gamma_{m}$ (moist bulk specific weight) and $c_{t}$ (total soil cohesion) involves the assessment of the water storage in the unsaturated zone (the zone between the steadystate water table and the land surface). For steady vertical water flow in the unsaturated zone, Darcy's law gives (Rockhold et al., 1997):

$Z_{T}-Z_{B}=\int_{\psi_{B}}^{\psi_{T}} \frac{d \psi}{N / k(\psi)-1}$

where $Z$ is the depth, $\psi$ is the soil-water suction (negative pressure head), $N$ is the steady-state recharge flux, $k(\psi)$ is the hydraulic conductivity, and subscripts $T$ and $B$ denote the top and bottom, respectively, of a layer with uniform, homogeneous hydraulic properties. Note that Eq. (6) is written such that $Z$ is positive downward and $N$ is positive for infiltration. An exact analytical solution to Eq. (6) was obtained by Gardner (1958) using the exponential $k(\psi)$ function:

$k(\psi)=k_{s} \exp (-\alpha \psi)$

where $k_{s}$ is the saturated hydraulic conductivity and $\alpha$ is a parameter. The resulting analytical solution to Eq. (6) is:

$Z_{T}-Z_{B}=\psi_{T}-\psi_{B}+\frac{1}{\alpha} \ln \left[\frac{\lambda e^{\psi_{B} \alpha}-1}{\lambda e^{\psi_{T} \alpha}-1}\right]$

where $\psi_{T}$ and $\psi_{B}$ are the soil-water suction head at the top and bottom of each layer respectively and $\lambda=N / k_{s}$. From Eq. (8) and the soil water retention characteristic, the soil moisture $(\theta)$ profile can be determined. Here we use the van Genuchten equation (van Genuchten, 1980):

$\theta(\psi)=\theta_{r}+\left(\theta_{s}-\theta_{r}\right)\left[1+\left(\alpha_{v} \psi\right)^{n_{v}}\right]^{-m_{v}}$ 
to model the soil water retention characteristic. The parameters $\alpha_{v}$ and $n_{v}$ are empirical constants that affect the shape of the function and $m_{v}=1-1 / n_{v}$. The parameters $\theta_{r}$ and $\theta_{s}$ are the residual and saturated water content, respectively. Combining Eqs. (8) and (9) allows the computation of the soil moisture profile in the unsaturated zone. We are now able to derive the average soil moisture content in the unsaturated zone, which allows computing the moist bulk specific weight $\left(\gamma_{m}\right)$ at each position along the hillslope.

With respect to the influence of soil suction on the slope stability, Fredlund (1978) proposed a linear shear strength equation for an unsaturated soil. According to this model, the total cohesion of the soil can be calculated as:

$c_{t}=c_{e}+\left(u_{a}-u_{v}\right) \tan \phi^{b}$

where $c_{e}$ is the effective cohesion of saturated soil, $\left(u_{a}-u_{v}\right)$ is the matric suction of the soil on the plane of failure where $u_{a}$ and $u_{v}(\mathrm{kPa})$ are the pressures of pore air and pore water, respectively. In other words, $\left(u_{a}-u_{v}\right)$ equals the soil water suction expressed in $\mathrm{kPa}$. For slope stability analysis, the pore air pressure is assumed to be atmospheric and constant. $\phi^{b}$ is the angle of shearing resistance with respect to matric suction (degrees). It has been demonstrated (e.g. Gan et al., 1988; Oeberg and Sallfors, 1997) that $\phi^{b}$ is a nonlinear function of matric suction, however, it is difficult to determine the detailed pattern of decreasing $\phi^{b}$ with increasing suction (Jiao et al., 2005). Vanapalli et al. (1996) proposed that the relation between $\phi^{b}$ and $\phi$ is determined by the degree of saturation as follows:

$c_{t}=c_{e}+\left(u_{a}-u_{v}\right)\left(\frac{\theta-\theta_{r}}{\theta_{s}-\theta_{r}}\right) \tan \phi$

Substituting the average soil moisture content and the average soil water suction into Eq. (11) leads to a value of the soil cohesion in the unsaturated zone for each position along the hillslope. Finally, the total soil cohesion at each position is calculated as a weighted average of the soil cohesion in the unsaturated and saturated zone.

\section{Different methods for hillslope stability analysis}

\subsection{Infinite slope method}

First we generalize the infinite slope method by incorporating the effects of the unsaturated zone into Eq. (4). If we assume the height of the water table, the moist bulk specific weight and the total soil cohesion to be dependent on the $x$ coordinate, the local factor of safety can be calculated as:

$$
F S(x)=\frac{c_{t}(x)+\left[(1-\sigma(x)) \gamma_{m}(x)+\sigma(x) \gamma_{b}\right] D(x) \cos ^{2} \beta(x) \tan \phi}{\left[(1-\sigma(x)) \gamma_{m}(x)+\sigma(x) \gamma_{s}\right] D(x) \sin \beta(x) \cos \beta(x)}
$$

where $F S(x)$ is the factor of safety at location $x$ along the hillslope. Note that $\gamma_{m}$ is calculated based on the weight of dry soil and the soil moisture content (Eq. 9) at each position along the hillslope.
Obviously, Eq. (12) defines the factor of safety at a given location along the hillslope where soil depth and slope angle are constant. In order to derive the $\overline{F S}$ for the entire hillslope given a steady-state rainfall input, the following expression is proposed:

$$
\overline{F S}=\frac{\int_{0}^{L}\left\{c_{t}(x)+\left[(1-\sigma(x)) \gamma_{m}(x)+\sigma(x) \gamma_{b}\right] D(x) \cos ^{2} \beta(x) \tan \phi\right\} d x}{\int_{0}^{L}\left[(1-\sigma(x)) \gamma_{m}(x)+\sigma(x) \gamma_{s}\right] D(x) \sin \beta(x) \cos \beta(x) d x}
$$

\subsection{More complex approaches toward hillslope stability}

Limit equilibrium methods have been used for decades to safely design major geotechnical structures. Bishop's simplified method, utilizing a circular arc slip surface, is probably the most popular limit equilibrium method (Han and Leshchinsky, 2004). Although Bishop's method is not rigorous in the sense that it does not satisfy horizontal force limit equilibrium, it is simple to apply and, in many practical problems, it yields results close to rigorous limit equilibrium methods. In this paper Bishop's simplified method (1955) and Janbu's non-circular method (1954) were used for the hillslope stability analysis. Bishop's method assumes zero interslice shear forces, satisfies moment equilibrium around the center of circular failure surface and vertical force equilibrium. The factor of safety according to this method is computed as:

$$
F S=\frac{\int_{0}^{L}\left[c_{t}(x) / \cos \beta(x)+(P(x)-u(x) / \cos \beta(x)) \tan \phi\right] d x}{\int_{0}^{L} W(x) \sin \beta(x) d x}
$$

where

$$
P(x)=\left[W(x)-\frac{1}{F S}\left(c_{t}(x) \tan \beta(x)-u(x) \tan \beta(x) \tan \phi\right)\right] / M(x)(15)
$$

and

$M(x)=\left(1+\tan \beta(x) \frac{\tan \phi}{F S}\right) \cos \beta(x)$

In the Janbu method, the assumption is made that the interslice shear forces are zero and thus the expression obtained from the total normal force at the base of each slice is the same as that obtained by Bishop method. To allow for the effect of the interslice shear force, a correction factor $f_{0}$ is applied (taken to be 1 here); thus the factor of safety of the slope $(F S)$ in the Janbu method is given as:

$$
F S=f_{0} \frac{\int_{0}^{L}\left[c_{t}(x) / \cos \beta(x)+(P(x)-u(x) / \cos \beta(x)) \tan \phi\right] / \cos \beta(x) d x}{\int_{0}^{L} W(x) \tan \beta(x) d x}
$$

In these equations, $c_{t}$ is the total soil cohesion, $d x$ is the horizontal slice width, $u$ is the pore water pressure, $\phi$ is the effective angle of internal friction and $W(x) d x$ is the weight of a soil slice. The computation of $W$ involves the assessment 
of the water storage in the unsaturated zone (Sect. 3). Since Eqs. (14) and (17) are implicit equations in $F S$, this set of equations must be solved iteratively.

4.3 Reference case: neglecting the effect of the unsaturated zone

For all three slope stability methods presented above, we also consider the simplifying situation where the unsaturated zone does not play a role in the steady-state hydrology. For the infinite slope method, the assumption of the same bulk specific weight above and below the water table leads to following simplification of Eq. (13):

$$
\overline{F S}=\frac{\int_{0}^{L}\left[c_{t}(x)+\left(\gamma_{s}-\sigma(x) \gamma_{w}\right) D(x) \cos ^{2} \beta(x) \tan \phi\right] d x}{\int_{0}^{L} \gamma_{S} D(x) \sin \beta(x) \cos \beta(x) d x}
$$

In case of the complex slope stability approach Eqs. (14$17)$, the safety factor can be calculated by considering $u(x)=\gamma_{w} h(x) \cos \beta(x)$ and $W(x)=\gamma_{s} D(x)$, where $h=S /(w f)$ (see Troch et al., 2002). By incorporating $u$ (based on $S$, the saturated soil storage) and $W$ (based on $\gamma_{s}$, the specific weight of the saturated soil), the presented models can be used for hillslopes with different geometrical characteristics (plan shape and profile curvature) and constant or non-constant soil depth. They can help understanding the hydrologic control of shallow and deep landslides in the case of steady-state hydrology.

\section{Results and discussion}

5.1 Evaluation of different approaches to model hillslope stability

To investigate the critical slip surface and effect of the unsaturated zone storage on slope stability, we evaluate 6 possible slope stability computations: Case $A$ : the same bulk specific weight for saturated and unsaturated storage and the infinite slope stability assumption (as in Talebi et al., 2007, our base case); Case $B$ : considering the soil moisture profile (unsaturated storage) and the infinite slope stability assumption; Case $C$ : the same bulk specific weight for saturated and unsaturated storage and Bishop's circular slip surface method; Case $D$ : considering the soil moisture profile (unsaturated zone storage) and Bishop's circular slip surface method; Case $E$ : the same bulk specific weight for saturated and unsaturated storage and Janbu's non-circular slip surface method; and finally Case $F$ : considering the soil moisture profile (unsaturated zone storage) and Janbu's non-circular slip surface method (see Table 1). We apply these 6 cases to nine different hillslope types. These nine characteristic hillslopes consist of three plan shapes (divergent, parallel, and convergent) and three profile curvatures (convex, straight,
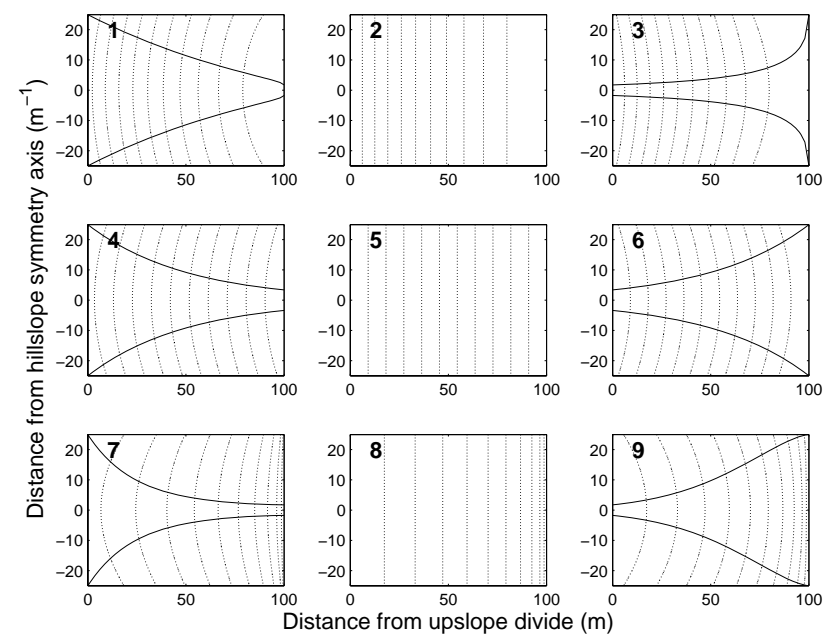

Fig. 1. Plan view of drainage divides (solid lines) and contour lines (dashed lines) of nine hillslope types $(\beta / \phi)=0.9)$. The upslope divide of each hillslope is at $x=0$.

Table 1. Hydrological assumptions and stability methods used in this study.

\begin{tabular}{llll}
\hline $\begin{array}{l}\text { Stability } \\
\text { Hydrology }\end{array}$ & Infinite slope & Bishop* & Janbu* \\
\hline $\begin{array}{l}\text { Constant bulk spe- } \\
\text { cific weight }\end{array}$ & $A$ & $C$ & $E$ \\
Saturated/Unsaturated & $B$ & $D$ & $F$ \\
\hline
\end{tabular}

* Note that for the Bishop and Janbu method, the soil depth is changed along the hillslope.

and concave). Figure 1 illustrates the nine basic hillslope types used in this study. The parameters to generate them are listed in Table 2. The horizontal length of the nine hillslopes is chosen to be constant $(L=100 \mathrm{~m})$, whereas the average slope is 26,41 and 50 percent $(\beta / \phi=0.5,0.75$ and 0.9$)$ for the infinite slope method. As the soil depth is changed along the $x$ direction in the complex slope stability approach, the bedrock slope and surface slope angle are assumed 30 and 50 percent $(\beta / \phi=0.6$ and 0.9$)$, respectively. These nine hillslopes represent a wide range of landforms traditionally considered in hydrology and geomorphology (Pennock et al., 1987). For different hillslopes within a catchment each individual hillslope type can be adjusted to the observed terrain profile curvature using the geometrical scaling parameters $H$, $L$, and $n$ and a proper choice of $\omega$ to represent plan shape.

\subsection{Hydrology}

Figure 2 shows the relative saturated storage along these hillslopes and Table 3 lists the values of the hydrological variables used to generate these storage profiles. The hydrological behavior of these hillslopes is quite different as can 
Table 2. Parameters for the nine characteristic hillslopes.

\begin{tabular}{llllll}
\hline $\begin{array}{l}\text { Hillslope } \\
\text { Nr. }\end{array}$ & $\begin{array}{l}\text { Profile } \\
\text { Curvature }\end{array}$ & Plan Shape & $n[-]$ & $\begin{array}{l}\omega \times 10^{-3} \\
{\left[\mathrm{~m}^{-1}\right]^{*}}\end{array}$ & Area $\left[\mathrm{m}^{2}\right]$ \\
\hline 1 & concave & convergent & 1.5 & +2.7 & 2441 \\
2 & concave & parallel & 1.5 & 0 & 5000 \\
3 & concave & divergent & 1.5 & -2.7 & 1049 \\
4 & straight & convergent & 1 & +2.7 & 2162 \\
5 & straight & parallel & 1 & 0 & 5000 \\
6 & straight & divergent & 1 & -2.7 & 2162 \\
7 & convex & convergent & 0.5 & +2.7 & 1402 \\
8 & convex & parallel & 0.5 & 0 & 5000 \\
9 & convex & divergent & 0.5 & -2.7 & 2268 \\
\hline
\end{tabular}

* This parameter has been calculated based on $\beta=15^{\circ}(\beta / \phi=0.5)$.

Table 3. Hydrological and geotechnical model parameters.

\begin{tabular}{|c|c|c|c|c|}
\hline Parameter group & Parameter name & Symbol & Units & Value \\
\hline \multirow[t]{7}{*}{ Hydrological } & $\begin{array}{l}\text { Saturated hydraulic conduc- } \\
\text { tivity }\end{array}$ & $K_{S}$ & $\mathrm{~ms}^{-1}$ & $6.383 * 10^{-5}$ \\
\hline & Effective porosity & $f$ & - & 0.34 \\
\hline & Recharge & $N$ & $\mathrm{~mm} \mathrm{~d}^{-1}$ & $\begin{array}{l}20 \text { (infinite } \\
\text { method) and } \\
50 \text { (complex } \\
\text { approach) }\end{array}$ \\
\hline & Van Genuchten parameter & $\alpha_{v}$ & $\mathrm{~m}^{-1}$ & 2.761 \\
\hline & Van Genuchten parameter & $n_{v}$ & - & 3.022 \\
\hline & Residual water content & $\theta_{r}$ & $\mathrm{~m}^{3} \mathrm{~m}^{-3}$ & 0.044 \\
\hline & Saturated water content & $\theta_{s}$ & $\mathrm{~m}^{3} \mathrm{~m}^{-3}$ & 0.375 \\
\hline \multirow[t]{5}{*}{ Geotechnical } & Effective soil cohesion & $c_{e}$ & $\mathrm{kN} \mathrm{m}^{-2}$ & 7.85 \\
\hline & $\begin{array}{l}\text { Effective angle of internal } \\
\text { friction }\end{array}$ & $\phi$ & $\circ$ & 30 \\
\hline & Slice & $d x$ & $\mathrm{~m}$ & 0.5 \\
\hline & $\begin{array}{l}\text { Saturated bulk } \\
\text { specific weight }\end{array}$ & $\gamma_{s}$ & $\mathrm{kN} \mathrm{m}^{-3}$ & 20.35 \\
\hline & Water specific weight & $\gamma_{w}$ & $\mathrm{kN} \mathrm{m}^{-3}$ & 9.81 \\
\hline
\end{tabular}

be seen from Fig. 2, e.g. hillslopes with convergent plan shape (1, 4 and 7) have the largest saturated section. For the rainfall recharge event $\left(20 \mathrm{~mm} \mathrm{~d}^{-1}\right)$ and slope angle (27 degrees, $\beta=0.9 \phi$ ) chosen, hillslopes $1,2,4$ and 7 saturate near the outlet. This hydrological behavior of hillslopes (storage changes) has important consequences for slope stability, as will be discussed hereafter.

In the procedure adopted to model the unsaturated zone pore water pressure and soil moisture, each hillslope is divided into a series of rectangular vertical columns or slices, each subdivided into regular cells. Using Eq. (8) and considering $\psi_{B}=0$ at the water table, $\psi_{T}$ (the soil-water suction) for all cells in each column can be obtained. Figure 3 shows the steady state soil moisture profiles that develop in the un- saturated zone above the water table for each hillslope type (assuming a constant soil depth). In the hillslopes with a divergent plane shape, subsurface saturation is limited and as a result, the range of soil moisture profiles is small, in the sense that the depth to the saturated layer is more uniform in these cases (Fig. 3). Although soil moisture dynamics is the result of complex interaction between many elements like climate, soil, vegetation etc, this analysis shows that spatial soil moisture changes under steady-state conditions are strongly influenced by hillslope geometry (especially plan shape). This has also been shown by other studies (e.g. Qiu et al., 2001; Pellenq et al., 2003; Ridolfi et al., 2003; Hilberts et al., 2007). 


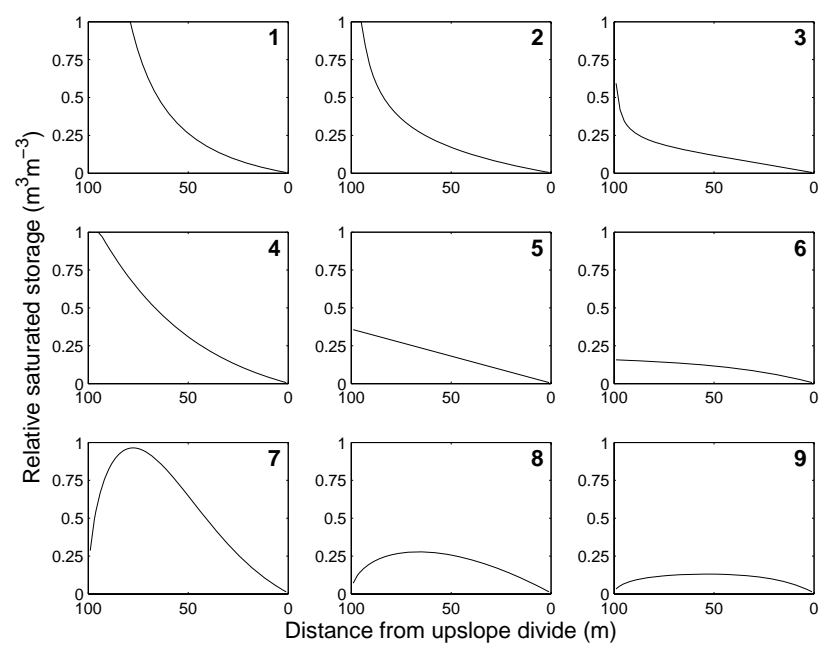

Fig. 2. Relative saturated storage along the different hillslopes $\left(D=2 \mathrm{~m}, N=20 \mathrm{~mm} \mathrm{~d}^{-1}, \beta=27^{\circ}\right.$ and $\left.\beta / \phi=0.9\right)$.
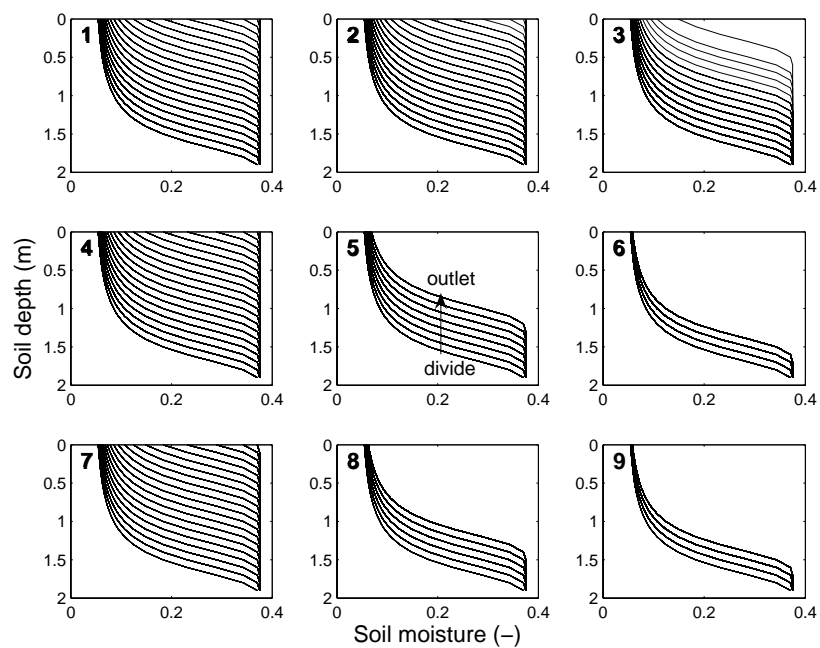

Fig. 3. Range of soil moisture profiles corresponding to a steady-state recharge $\left(20 \mathrm{~mm} \mathrm{~d}^{-1}\right)$ for the different hillslopes $\left(\beta=27^{\circ}, \beta / \phi=0.9\right.$ ), between $x=0$ and $x=L$. The arrow (hillslope no. 5) indicates increasing values of the $\mathrm{x}$-coordinate.

\subsection{Infinite slope stability analysis}

Figure 4 reports the values of the safety factor for each hillslope and for a range of average bedrock slope angles using the infinite slope method (constant soil depth) for the two cases: with and without considering the unsaturated zone storage (Cases $A$ and $B$ ). In this figure, the solid lines have been calculated by Eq. (18) (case $A$ ) which assumes the bulk specific weight above and below the water table is equal. The dashed lines have been obtained by Eq. (13) (case $B$ ), which is based on the calculation of the soil moisture profile in the unsaturated zone (Eq. 8) and the relative saturated soil moisture storage (Eq. 3). The effect of matric suction
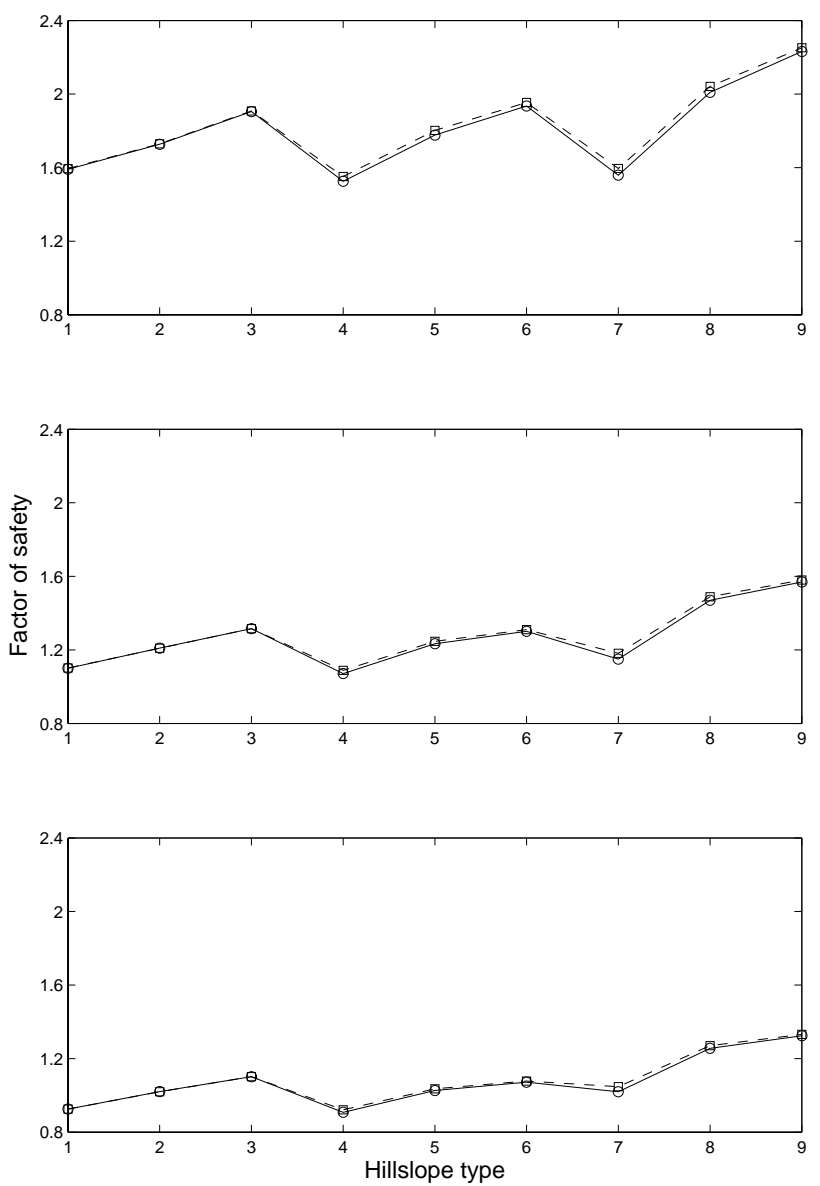

Fig. 4. Factor of safety for nine hillslopes and different average slope angles. Solid lines (Case $A$ ): the bulk specific weight above and below the water table is the same and the infinite slope stability assumption is applied (as in Talebi et al., 2007); Dashed lines (Case $B)$ : the unsaturated storage is taken into account and the infinite slope stability assumption is applied; Average bedrock slope angle is different for each row; from top to bottom: 15, 22.5 and 27 degrees $(\beta / \phi=0.5,0.75,0.9)$.

on soil cohesion also has been incorporated in the stability analysis (Eq. 11). Because divergent hillslopes (3, 6 and 9) have the smallest saturated zone (see Fig. 2), they exhibit the most stability in both cases. On the other hand, for a given profile curvature, convergent hillslopes $(1,4$ and 7$)$ have the least stability because they have the largest saturated zone (see Fig. 2). As can be seen (Fig. 4), both methods yield comparable results, illustrating the hillslope stability is determined by the water table dynamics (saturated soil moisture storage). This means that unsaturated zone storage does not play a critical role in determining the factor of safety for shallow landslides. Hence, the bulk specific weight of the unsaturated zone can be considered equal to that of the saturated zone in the steady-state hydrology.

To generalize the obtained results for the infinite slope method, the slope stability has also been investigated in the 


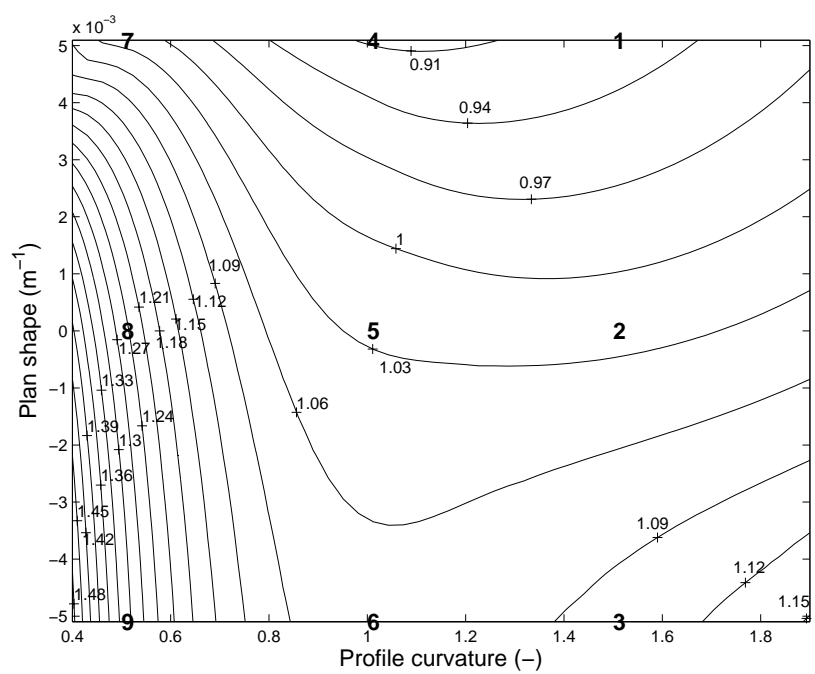

Fig. 5. Factor of safety as a function of profile curvature $(n)$ and plan shape $(\omega)$ for case $B$ : considering the soil moisture profile in the unsaturated zone and the infinite slope stability assumption $(\beta / \phi=0.9)$. The bold numbers shows the location of the nine basic hillslopes.

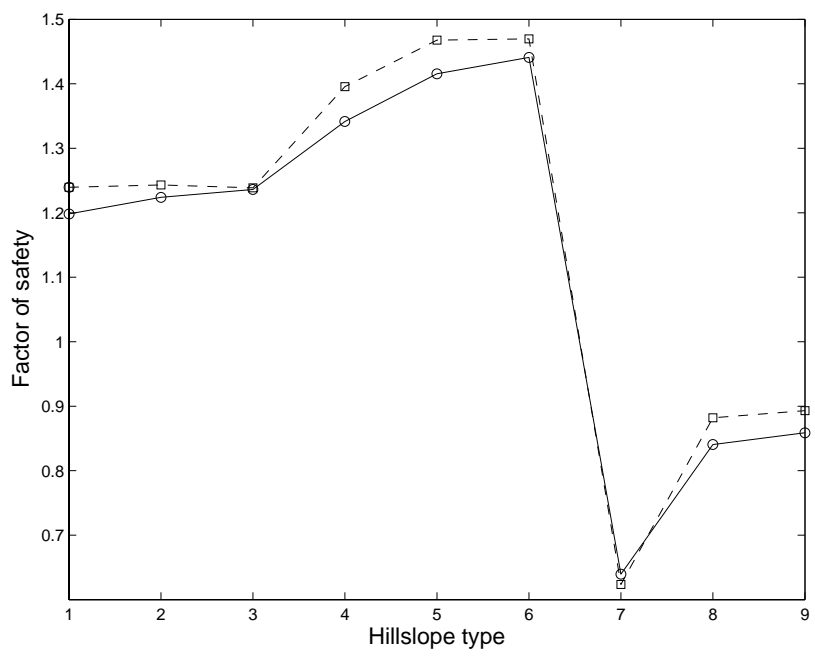

Fig. 6. Factor of safety for nine hillslope shapes. Solid lines (Case $C)$ : considering the same bulk specific weight above and below the water table and Bishop's circular slip surface method. Dashed lines (Case $D$ ): taking into account the unsaturated storage and Bishop's circular slip surface method. Average bedrock slope is 30 and 50 percent for bedrock and surface, respectively.

$n-\omega$ parameter space considering the unsaturated zone storage. On the basis of Eq. (1), and for the parameter intervals $0.4<n<1.9$ and $-\left(H / L^{2}\right)<\omega<+\left(H / L^{2}\right)$ (for $L=100$ ), the factor of safety has been calculated. Figure 5 illustrates the relation of the safety factor with profile curvature $(n)$ and plan shape $(\omega)$ for a critical slope angle $(\beta / \phi=0.9)$. For any given plan shape $(\omega=\mathrm{cst})$, when profile curvature $(n)$ changes from convex to concave, stability decreases. In the case of plan shape, when it changes from $\omega<0$ to $\omega>0$ (from divergent to convergent), slope stability decreases in all profiles. This is due to the effect of plan shape on saturated soil storage (Troch et al., 2002, Hilberts et al., 2004). When plan shape changes from divergent to convergent, the soil moisture storage increases in all profiles (see Fig. 2). In both cases, the convergent hillslopes with concave profile have the least stability. For the convex profiles $(n<1)$, the effect of plan shape on hillslope stability is more pronounced than for the other profiles: as plan shape changes from divergent to convergent, $F S$ drops quickly. For concave bedrock profiles $(n>1)$, stability decreases slightly when plan shape changes from divergent $(\omega<0)$ to convergent $(\omega>0)$.

\subsection{Bishop and Janbu methods}

Hillslope stability has also been investigated for hillslopes with non-constant soil depth (deep landslides) using more complex approaches: Bishop's and Janbu's methods taking the soil moisture in the unsaturated zone and its effect on soil cohesion into consideration. To do this, the Bishop circular method is incorporated into the analytical model to find the critical slip surface in hillslopes with different geometric characteristics. Here, we consider a series of slip circles of different radii but with the same center of rotation and find the minimum $F S$ for this circle center. This procedure is repeated for several circles, each investigated from an array of centers. Each center will have a minimum $F S$, and the overall lowest $F S$ from all the centers is considered to be the $F S$ for the whole hillslope. Hence, a large number of possible slips (6000) has been considered for the calculation of the minimum safety factor. Finally, by assuming the same slip surface for all hillslopes (namely the bedrock), the safety factor is computed by Janbu's non-circular method.

Figure 6 shows the values of the minimum safety factor for each hillslope and for the two cases: with and without considering the unsaturated storage. The final results of both cases are similar and the previous conclusion that the unsaturated zone can be neglected is confirmed for hillslopes with non-constant soil depth. Figure 6 shows that when plan shape changes from convergent to divergent, for all profiles slope stability increases. In both cases the convex convergent hillslopes have the minimum safety factor as convex hillslopes have a large slope angle in the outlet region.

The slip surface corresponding to the minimum FS has also been investigated. Figure 7 illustrates the location of the critical slip surface as computed by the Bishop simplified method (circular slip surface) for case $D$. The bedrock and surface slope angle are 30 and 50 percent, respectively (non-constant soil depth). As can be seen, not only the FS is different for all hillslopes, but also the location of the critical slip surface has changed. It is located in the upstream part of the slope for the concave and in the downstream part of the slope for the convex profiles. The location of the critical slip 

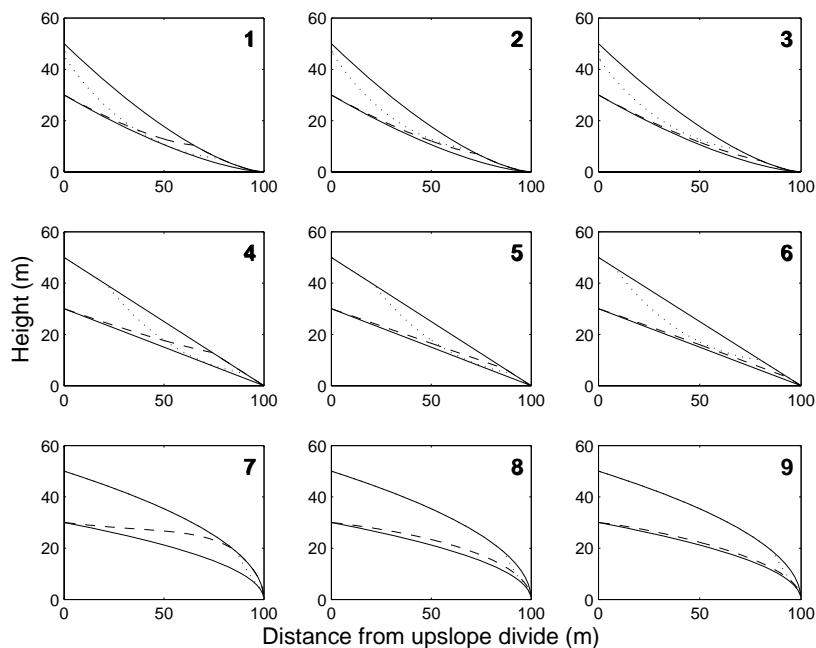

Fig. 7. The critical slip surface (dotted lines) in hillslopes with different geometric characteristics as computed by Bishop's circular slip surface method and considering the unsaturated zone storage (case $D$ ). The dashed lines show the location of the water table. Average bedrock slope (bottom solid line) and surface slope angle (top solid line) are 30 and 50 percent, respectively.

surface is dependent on the profile curvature but much less on plan shape (specifically for the convex profiles). This is because the stability strongly depends on the local slope angle, although, plan shape also affects stability by increasing the saturated part near the outlet.

In order to generalize the obtained results for hillslopes with non-constant soil depth, slope stability has again been investigated in the $n-\omega$ parameter space considering the unsaturated zone storage. Figure 8 indicates the obtained $F S$ for the different values of $n$ (profile curvature) and $\omega$ (plan shape). For any given plan shape $(\omega=\mathrm{cst})$, when profile curvature changes from straight to concave or convex, stability decreases because concave and convex hillslopes have a large slope angle in the upstream and downstream parts of the slope, respectively. Hillslopes with a small degree of convexity $(n=0.9)$ have the maximum safety factor (see Fig. 8). For concave profiles $(n>1)$, the contour lines are almost parallel, indicating a weaker effect of plan shape on stability. Finally, hillslopes with a convex length profile and convergent plan shape have the least stability. Furthermore, there is no significant difference between the results of both cases $(C$ and $D$ ), which confirms again that the unsaturated zone storage can be neglected for the slope stability analysis in the case of steady-state hydrology.

To compare the stability of hillslopes by assuming the same slip surface on the bedrock, the $F S$ is also calculated by the Janbu non-circular method. Figure 9 shows the stability of nine hillslopes when the soil depth changes along the hillslopes. According to this method, when the slip surface lies on the bedrock, the convex hillslopes are the most sta-

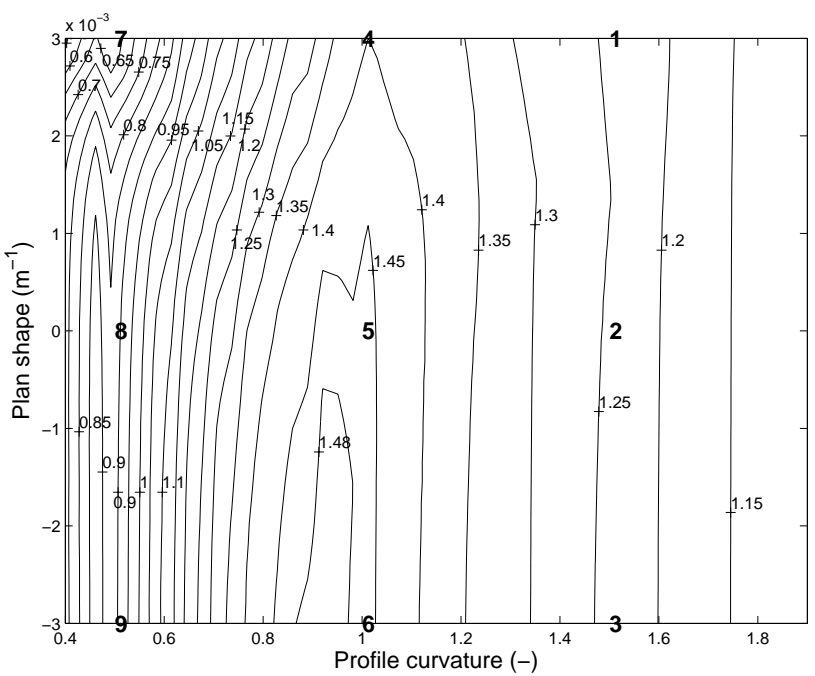

Fig. 8. Factor of safety as function of profile curvature $(n)$ and plan shape $(\omega)$ using the more complex approach (Bishop's circular slip surface method and non-constant soil depth), and considering the soil moisture in the unsaturated zone (case $D$ ). Average bedrock slope is 30 and 50 percent for bedrock and surface, respectively. The bold numbers shows the location of the nine basic hillslopes.

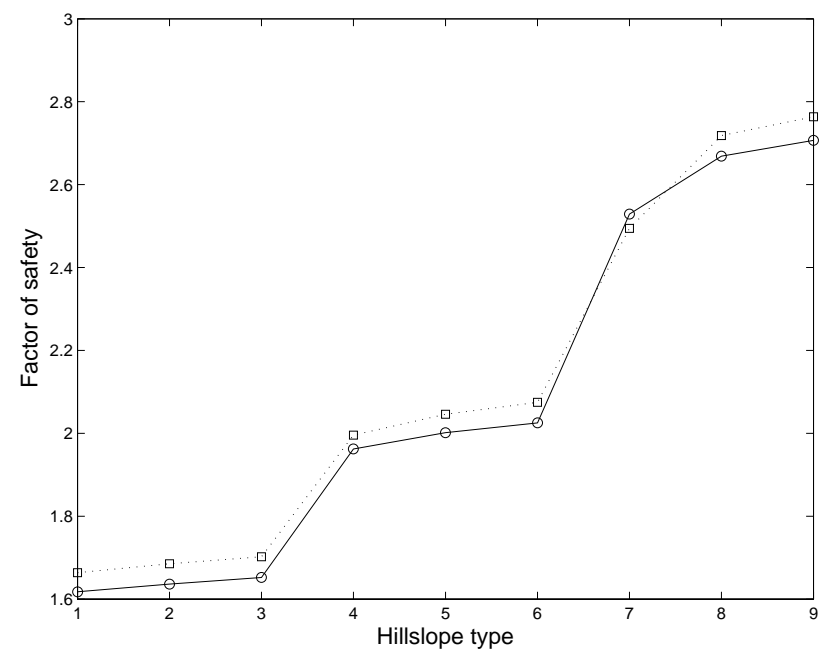

Fig. 9. Factor of safety for nine hillslope shapes. Solid lines (Case $E$ ): considering the same bulk specific weight above and below the water table and Janbu non-circular slip surface method. Dashed lines $($ Case $F$ ): taking into account the unsaturated storage and Janbu non-circular slip surface method. Average bedrock slope is 30 and 50 percent for bedrock and surface, respectively.

ble and the concave ones are the least stable. For all profile curvatures, slope stability slightly increases when plan shape changes from convergent to divergent.

This is confirmed by Fig. 10, where we have computed the $F S$ for a wide range of plan shapes and profile curvatures. When profile curvature changes from concave to convex, 


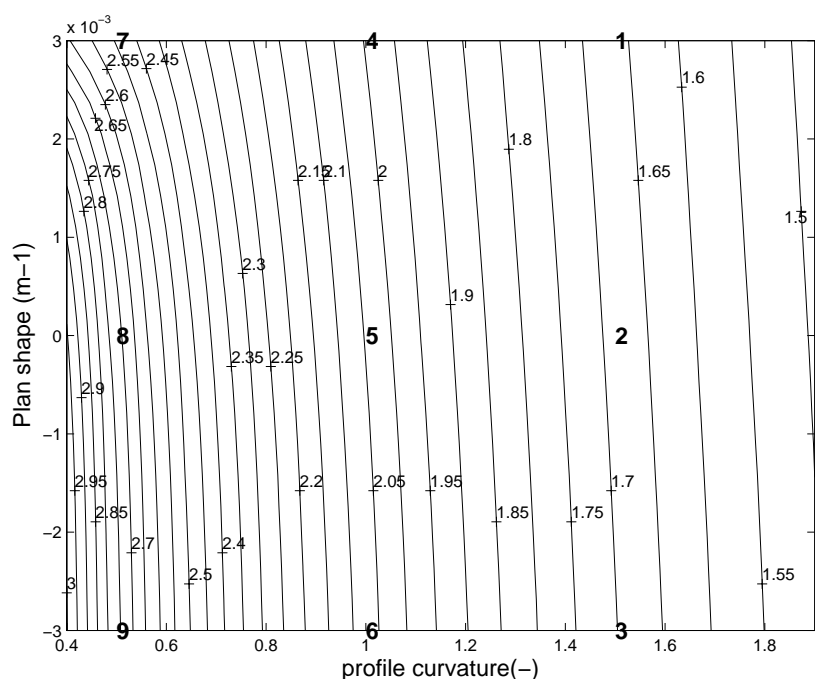

Fig. 10. Factor of safety as function of profile curvature $(n)$ and plan shape $(\omega)$ using the more complex approach (Janbu non-circular slip surface method and non-constant soil depth), and considering the soil moisture in the unsaturated zone (case $D$ ). Average bedrock slope is 30 and 50 percent for bedrock and surface, respectively. The bold numbers shows the location of the nine basic hillslopes.

stability decreases. The fact that the contour lines are nearly parallel indicates that plan shape only plays a minor role. With respect to the similarity of the Bishop and Janbu methods (see Eqs. 14 and 17), it should be kept in mind that in this paper, the slip surface with the minimum FS has only been determined with the Bishop circular method. However, the Janbu non-circular method has been used for comparison of slope stability for entire hillslopes (when the slip surface lies on the bedrock). Overall, Fig. 10 illustrates how slope stability is changed when hillslope geometry and thus hillslope hydrology is varied.

\section{Summary and conclusions}

The aim of this paper was to analyze the role of the geometric characteristics of hillslopes as well as the effect of the unsaturated zone storage on the hillslope stability in the steady-state hydrology. This was studied on the basis of computing and analyzing the $F S$ in two different manners. First, an analytical model (Talebi et al., 2007) that is based on kinematic wave dynamics of the saturated subsurface storage and the infinite slope stability assumption (for a constant soil depth and shallow landslides). Second, a more complex approach (for a non-constant soil depth associated with deep landslides) that accounts for the unsaturated zone storage and that relaxes the simplifying assumptions of the infinite slope stability model (Janbu's non-circular method and Bishop's simplified method). All methods were studied in two cases: with and without considering the soil moisture profile in the unsaturated zone. The effect of soil suction on soil cohesion has also been investigated.

We started our analysis from the observation that the geometry (that is plan shape and profile curvature) of a hillslope exerts a major control on the hydrologic storage, by defining the domain and boundary conditions of moisture storage (Troch et al., 2002). The presented hydrological model (kinematic wave dynamics of saturated subsurface storage) takes into account the effects of topography on the hillslopestorage through the plan shape and profile curvature by computing the relative saturated soil moisture storage. We applied the considered hillslope stability models to nine characteristic hillslope types with three different profile curvatures (concave, straight, convex) and three different plan shapes (convergent, parallel, divergent). Furthermore, in order to generalize the results, we also applied the slope stability models to a wider range of plan shapes and profile curvatures. Our conclusions are the following:

1. When the width function (plan shape) changes from convergent to divergent, hillslope stability generally increases. In case of the infinite slope method for shallow landslides (with and without the unsaturated zone storage), the convergent hillslopes with concave profile curvature have the least stability in both cases. The divergent convex hillslopes have the most stability as they have less storage than other hillslopes.

2. To find the critical slip surface in the hillslopes with non-constant soil depth, the simplified Bishop method was incorporated in the analytical model. In this case, not only the rate of $F S$ is different in the hillslopes but also the location of the critical slip changes. In fact, the critical slip surface is located at the upstream end of the slope in the concave hillslopes and near the outlet in the convex hillslopes. This is because the local slope angle (profile curvature) has a key role in the slope stability. Therefore, it can be concluded that the location of the critical slip surface is more dependent on profile curvature than on plan shape. Overall, for a given plan shape (convergent, parallel or divergent) convex convergent hillslopes have slip surfaces with the minimum safety factor in the outlet region.

3. To compare the stability of entire hillslopes, the Janbu non-circular method was incorporated in the analytical model with its slip surface at the bedrock. This method also shows that the convergent hillslopes with concave profile curvature have the least stability.

4. A comparison of the results of the different slope stability models with and without considering the unsaturated zone storage shows that there is no noticeable difference between the two cases. This means that the bulk specific weight of the unsaturated soil can be considered equal to that of the saturated soil in the steady-state hydrology. Hence, the hillslope stability $(F S)$ is completely 
determined by the water table dynamics. Therefore the effect of the unsaturated zone storage can be neglected safely in the steady-state hydrology.

5. Finally, it can be stated that the incorporated more complex approach (simplified Bishop method and Janbu's non-circular method) and steady-state hydrology model based on the relative saturated storage can help to predict the critical slip surface and slope stability for hillslopes with different geometrical characteristics but due to its limitation (steady-state hydrology) more research is needed to account for dynamical slope stability effects.

Acknowledgements. The first author is sponsored by the Ministry of Science, Research and Technology of the Islamic Republic of Iran. The second author is financially supported by the Netherlands Organization for Scientific Research (NWO) through a grant (016.021.003) in the framework of the Innovational Research Incentives Scheme (Vernieuwingsimpuls).

Edited by: T. Glade

Reviewed by: two anonymous referees

\section{References}

Anderson, M. G. and Kemp, M. J.: Towards an improved specification of hillslope hydrology in the analysis of slope instability problems in the tropics, Progress in Physical Geomorphology, 15(1), 29-52, 1991.

Bishop, A. W.: The use of the slip circle in the stability analysis of slopes, Geotechnique 5(1), 7-77, 1955.

Borga, M., Fontana, G. D., Gregoretti, C., and Marchi, L.: Assessment of shallow landsliding by using a physically based model of hillslope stability, Hydrol. Process., 16, 2833-2851, 2002.

Claessens, L.: Modeling Land slide Dynamics in Forested Landscapes, PhD thesis, Wageningen University, p.143, 2005.

Evans, I. S.: An integrated system of terrain analysis and slope mapping, Z. Geomorph. NF Suppl-Bd, 36, 274-295, 1980.

Fan, Y. and Bras, R. L.: Analytical solutions to hillslope subsurface storm flow and saturation overland flow, Water Resour. Res., 34(4), 921-927, 1998.

Fredlund, D. G., Morgenstern, N. R., and Widger, R. A.: The shear strength of unsaturated soil, Can. Geotech. J., 15, 313-321, 1978.

Gan, J. K., Fredlund, D. G., and Rahardjio, H.: Determination of shear strength parameters of an unsaturated soil using the direct shear test, Can. Geotech. J., 25, 500-510, 1988.

Gardner, W. R.: Some steady-state solutions of the unsaturated moisture flow equation with application to evaporation from a water table, Soil Sci., 85, 228-332, 1958.

Han, J. and Leshchinsky, D.: Limit equilibrium and continuum mechanics-based numerical methods for analyzing stability of MSE walls, 17th ASCE Engineering Mechanics Conference, 1316 June, University of Delaware, Newark, DE, USA, 2004.

Hennrich, K. and Crozier, M. J.: A hillslope hydrology approach for catchment-scale slope stability analysis, Earth Surf. Process. Landforms, 29, 599-610, 2004.

Hilberts, A. G. J., Troch, P. A., Paniconi, C., and Boll, J.: Lowdimensional modeling of hillslope subsurface flow: Relationship between rainfall, recharge, and unsaturated storage dynamics, Water Resour. Res., 43, W03445, doi:10.1029/2006WR004964, 2007.

Janbu, N.: Application of composite slip surface for stability analysis, Proceedings of the European Conference on the Stability of Earth Slopes, 3, 43-49, 1954.

Jiao, J. J., Wang, X. S., and Nandy, S.: Confined groundwater zone and slope instability in weathered igneous rocks in Hong Kong, J. Eng. Geol., 80, 71-92, 2005.

Montgomery, D. R. and Dietrich, W. E.: A physically based model for the topographic control on shallow landsliding, Water Resour. Res., 30, 1153-1171, 1994.

Montgomery, D. R., Sullivan, K., and Greenberg, H. M.: Regional test of a model for shallow landsliding, Hydrol. Process., 12, 943-955, 1998.

Oeberg, A. L. and Saellfors, G.: Determination of shear strength parameters of unsaturated silts and sand based on the water retention curve, Geotech. Test. J., 20(1), 40-48, 1997.

Pellenq, J., Kalma, J., Boulet, G., Saulnier, G. M., Wooldridge, S., and Kerr, Y.: A disaggregation scheme for soil moisture based on topography and soil depth, J. Hydrol., 276, 112-127, 2003.

Pennock, D. J., Zebarth, B. J., and De Jong, E.: Landform classification and soil distribution in Hummocky Terrain, Saskatchewan, Canada, Geoderma, 40, 297-315, 1987.

Qiu, Y., Fu, B., Wang, J., and Chen, L.: Soil moisture variation in relation to topography and land use in a hillslope catchment of the Loess Plateau, China, J. Hydrol., 240, 243-263, 2001.

Ridolfi, L., D’Odorico, P., Porporato, A., and Rodriguez-Iturbe, I.: Stochastic soil moisture dynamics along a hillslope, J. Hydrol. 272, 264-275, 2003.

Rockhold, M. L., Simmons, C. S., and Fayer, M. J.: An analytical solution technique for one-dimensional, steady vertical water flow in layered soils, Water Resour. Res., 33, 897-902, 1997.

Sidle, R. C.: A theoretical model of the effects of timber harvesting on slope stability, Water Resour. Res., 28(7), 1897-1910, 1992.

Talebi, A., Troch, P. A., and Uijlenhoet, R.: A steady-state analytical hillslope stability model for complex hillslopes, Hydrol Process., in press, 2007.

Troch, P. A., Van Loon, E., and Hillberts, A.: Analytical solutions to a hillslope-storage kinematic wave equation for subsurface flow, Adv. Water Resour., 25, 637-649, 2002.

Vanapalli, S. K., Fredlund, D. G., Pufahl, D. E., and Clifton, A. W.: Model for the prediction of shear strength with respect to soil suction, Can. Geotech. J., 33(3), 379-392, 1996.

Van Beek, H.: Assessment of the influence of changes in land use and climate on landslide activity in a Mediterranean environment, PhD thesis, Utrecht University, 2002.

Van Genuchten, M. T.: A closed-form equation for predicting the hydraulic conductivity of unsaturated soils, Soil Sci. Soc. Am. J., 44, 892-898, 1980.

Waldron, L. J. and Dakessian, S.: Soil reinforcement by roots: calculation of increased soil resistance from root properties, Soil Sci., 132, 427-434, 1981.

Wilkinson, P. L., Brooks, S. M., and Anderson, M. G.: Design and application of an automated non-circular slip surface search within a combined hydrology and stability model (CHASM), Hydrol. Process., 14, 2003-2017, 2000. 
A. Talebi et al.: Soil moisture storage and hillslope stability

Wilkinson, P. L., Anderson, M. G., Lloyd, D. M., and Renaud, J. P.: An integrated hydrological model for rain-induced landslide prediction, Earth Surf. Process. Landforms, 27, 1285-1297, 2002.
Wu, W. and Siddle, R. C.: A distributed slope stability model for steep forested basins, Water Resour. Res., 31(8), 2097-2110, 1995. 